\title{
Effects of inulin propionate ester on obesity-related metabolic syndrome and intestinal microbial homeostasis in diet-induced obese mice
}

Xiaozhen Zhu' ${ }^{1,2}$, Xia Zhang ${ }^{1,2}$, Xuelu Gao ${ }^{2,3}$, Yuetao $\mathrm{Yi}^{*}{ }^{*}$ 1,5, Yang $\mathrm{Hou}^{7}$, Xianyao Meng ${ }^{1,2}$, Chenchen Jia ${ }^{1,2}$, Bo Chao ${ }^{6}$, Wenyong Fan ${ }^{6}$, Xinrui Li ${ }^{6}$, Hanhan Zhang*,4

${ }^{1}$ Yantai Institute of Coastal Zone Research, Chinese Academy of Sciences, Yantai 264003, China

${ }^{2}$ University of Chinese Academy of Sciences, Beijing 100049, China

${ }^{3}$ CAS Key Laboratory of Coastal Environmental Processes and Ecological Remediation, Yantai Institute of Coastal Zone Research, Chinese Academy of Sciences, Yantai 264003, China

${ }^{4}$ Department of Biochemistry and Molecular Biology, Key Laboratory of Tumor Molecular Biology in Binzhou Medical University, BinZhou Medical University, Yantai, Shandong, 264003, China

${ }^{5}$ Center for Ocean Mega-Science, Chinese Academy of Sciences, 7 Nanhai Road, Qingdao, 266071, China

${ }^{6}$ School of Clinical Medicine at BinZhou Medical University, 264003, China

${ }^{7}$ Beijing Dongcheng District Food and Drug Safety Monitoring Center, Beijing 100050, China

* Corresponding Author:

Email: ytyi@yic.ac.cn (Yuetao Yi)

Email: bettyonline@163.com (Hanhan Zhang)

Supporting information consists of 1 table (Tables S1) and 2 figures (Figure S1-S2) 
Table S1 The Diet composition of low-fat diet and high-fat diet.

\begin{tabular}{|c|c|c|c|c|}
\hline \multirow[t]{2}{*}{ Diet } & \multicolumn{2}{|c|}{ Low-fat diet } & \multicolumn{2}{|c|}{ High-fat diet } \\
\hline & gm $\%$ & Kcal\% & gm $\%$ & Kcal\% \\
\hline Protein & 19.2 & 20 & 26.2 & 20 \\
\hline Carbohydrate & 67.3 & 70 & 26.3 & 20 \\
\hline Fat & 4.3 & 10 & 34.9 & 60 \\
\hline Total & & 100 & & 100 \\
\hline $\mathrm{Kcal} / \mathrm{gm}$ & 3.85 & & 5.24 & \\
\hline Ingredient & $\mathrm{gm}$ & Kcal & $\mathrm{gm}$ & Kcal \\
\hline Casein, 80 Mesh & 200 & 800 & 200 & 800 \\
\hline L-Cystine & 3 & 12 & 3 & 12 \\
\hline Corn Starch & 315 & 1260 & 0 & 0 \\
\hline Maltodextrin 10 & 35 & 140 & 125 & 500 \\
\hline Sucrose & 350 & 1400 & 68.8 & 275.2 \\
\hline Cellulose, BW200 & 50 & 0 & 50 & 0 \\
\hline Soybean Oil & 25 & 225 & 25 & 225 \\
\hline Lard* & 20 & 180 & 245 & 2205 \\
\hline Mineral Mix S10026 & 10 & 0 & 10 & 0 \\
\hline DiCalcium Phosphate & 13 & 0 & 13 & 0 \\
\hline Calcium Carbonate & 5.5 & 0 & 5.5 & 0 \\
\hline Potassium Citrate, 1 H20 & 16.5 & 0 & 16.5 & 0 \\
\hline Vitamin Mix V1001 & 10 & 40 & 10 & 40 \\
\hline Choline Bitartrate & 2 & 0 & 2 & 0 \\
\hline FD\&C Blue Dye \#1 & & & 0.05 & 0 \\
\hline FD\&C Yellow Dye \#5 & 0.05 & 0 & & \\
\hline Total & 1055.05 & 4057 & 773.85 & 4057 \\
\hline
\end{tabular}
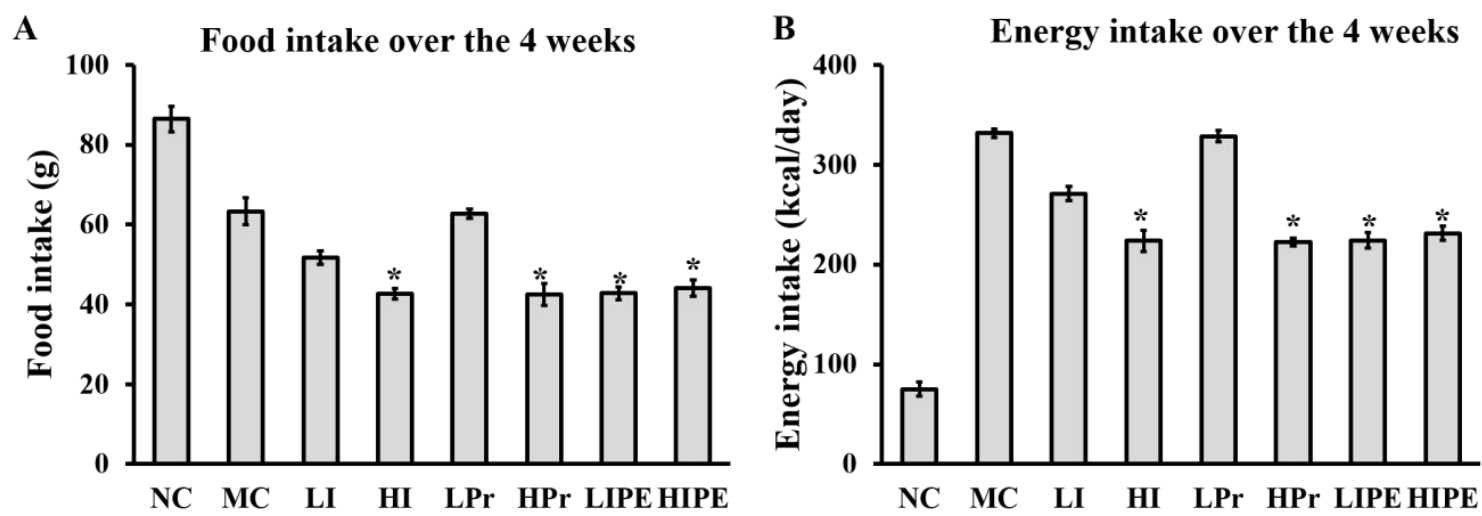

Figure S1 The cumulative food and energy intake over the 4 weeks in different groups. (A) The food intake over the 4 weeks; (B) Energy intake over the 4 weeks. *P $<0.05$ versus MC. 


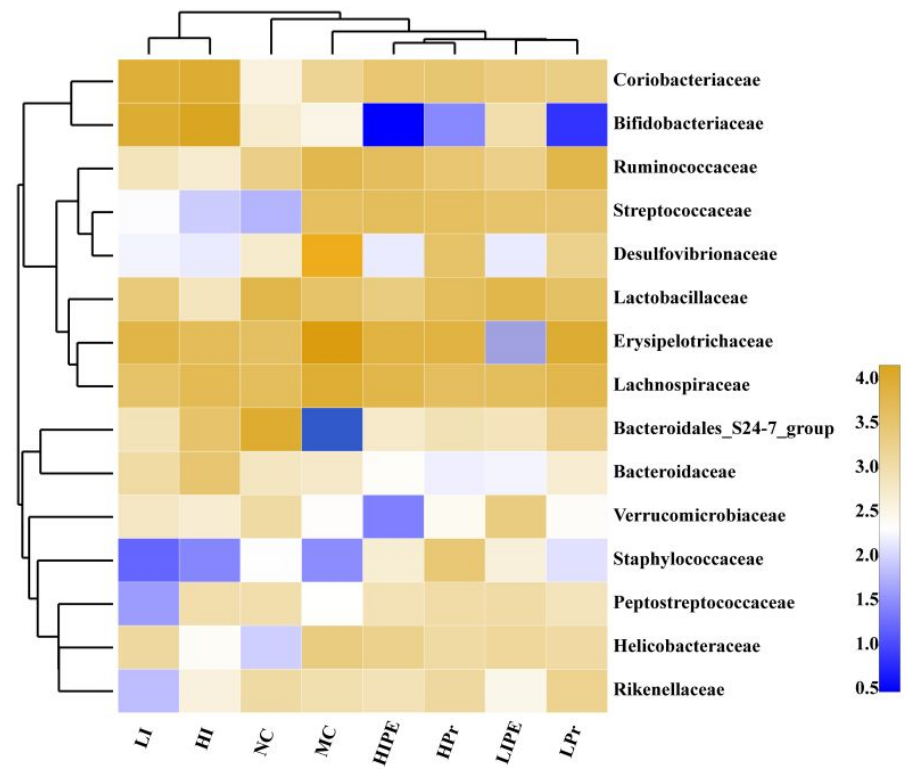

Figure S2 Heat map analysis of microbial community composition at family level 